\title{
Hydro-chemo-mechanical phase-field modeling of fracture propagation due to barite precipitation in porous media
}

\author{
DR. VANESSA MONTOYA ${ }^{1}$, JENNA POONOOSAMY ${ }^{2}$, \\ OLAF KOLDITZ $^{1,3}$ AND KEITA YOSHIOKA $^{1}$ \\ ${ }^{1}$ Helmholtz Centre for Environmental Research (UFZ) \\ ${ }^{2}$ Forschungszentrum Jülich GmbH \\ ${ }^{3}$ Dresden University of Technology \\ Presenting Author: vanessa.montoya@ufz.de
}

Upscaling of mineral precipitation and dissolution processes in porous media affecting the pore structure and subsequently the flow and transport properties in the continuum scale is a challenging task to be considered in mathematical models. To accurately model such processes, one needs conservation laws for mass and momentum in time-dependent domains where the evolution of the sharp interface separating two domains (i.e. mobile and immobile phases) is not known a priori. Therefore, a scheme accounting for moving/free boundary conditions, where the boundaries and hence the domains evolve, needs to be developed. Here, we present a new two-dimensional hydrochemo-mechanical phase-field fracture model to investigate the coupling of all the above mentioned processes. The model is developed/based on laboratory experimental studies and includes coupled morphological, rheological and geochemical changes that occurs from the presence of three mineral layers with different reactivity.

Following the approach of Poonoosamy and co-workers tank experiments [1], comprising the reaction of celestine $\left(\mathrm{SrSO}_{4}(\mathrm{~s})\right.$ with dissolved barium chloride $\left(\mathrm{BaCl}_{2 \text { (aq) }}\right)$ in water at $\mathrm{pH}=5.6$ to precipitate barite $\left(\mathrm{BaSO}_{4(\mathrm{~s})}\right)$ in porous media were employed to study fracture propagation due to the following dissolution/precipitation reaction:

$\mathrm{BaCl}_{2(\mathrm{aq})}+\mathrm{SrSO}_{4(\mathrm{~s})}-->\mathrm{SrCl}_{2(\mathrm{aq})}+\mathrm{BaSO}_{4(\mathrm{~s})}$

A concentrated solution of barium chloride $(0.3 \mathrm{~mol} / \mathrm{L})$ was injected in a porous media with different minerals layers (i.e. quartz sand and celestite) at a low flow rate of $20 \mu \mathrm{L} \mathrm{min}{ }^{-1}$. Celestine (strontium sulphate) is the only reactive mineral at the given chemical (i.e. $\mathrm{pH}$ and ionic strength), temperature and atmospheric pressure conditions (298.15 K and $1 \mathrm{~atm})$. As the $\mathrm{BaCl}_{2}$ solution reached the celestine, the precipitation of barite (barium sulphate) occurs as an end-member of a solid solution series. The injected solution front causes a reaction-pore clogging -induced fracturing which mimics basic features happening in low permeable rocks with pore sizes at the microscale. The model-based understanding of these sophisticated processes can be highly relevant in various geological systems and deep geological formations used for energy recovery, subsurface storage and waste disposal for example.

[1] Poonoosamy, Kosakowski, Van Loon, Mäder (2015) Journal of Contaminant Hydrology, 177-178, 1-17 